\title{
CHANGES OF THE QUALITY OF ACTIVATED SLUDGE DURING THE BIOLOGICAL TREATMENT OF LANDFILL LEACHATE
}

\begin{abstract}
The effect of chemically pretreated landfill leachate on the properties of activated sludge has been investigated. The leachate was pretreated by a two-stage method consisting of coagulation and oxidation. The mixture of pretreated leachate (from 2.5 to $15 \mathrm{wt} . \%$ ) and municipal wastewater was fed into a bioreactor. Results of the studies showed that the pretreated leachate contributed to the dispersion of the activated sludge flocs. As a result, a very low value of volume index $\left(30 \mathrm{~cm}^{3} / \mathrm{g}_{\mathrm{TS}}\right)$ and a significant turbidity of supernatant liquid were observed at the same time. The dispersion phenomenon was also confirmed by floc size distribution. An increase of the amount of small and very small flocs was observed.
\end{abstract}

\section{INTRODUCTION}

The most common method of treatment of municipal wastewater in Poland is biological processing using aerobic activated sludge. This method is also used in the treatment of various kinds of industrial wastewater susceptible to biological degradation [1-3]. Moreover the aerobic activated sludge effectively treats the mixture of domestic and industrial wastewater (in the case of discharging of industrial wastewater into drains and purifying them at a municipal wastewater treatment plant).

The aerobic activated sludge method is based on the intensification of the process of self-cleaning surface waters. Organic contaminants are mineralized by microorganisms belonging to activated sludge flocs. Nitrogen and phosphorus compounds are removed from wastewater during nitrification, denitrification and dephosphatation processes. These processes are also conducted by microorganisms. The flocs of activated sludge are agglomerations, mainly consisting of bacteria, ciliates, flagellates, rotifers,

${ }^{1}$ Faculty of Energy and Environmental Engineering, Silesian University of Technology, ul. Konarskiego 18A, 44-100, Gliwice, Poland, corresponding author B. Pieczykolan, e-mail: barbara.pieczykolan@polsl.pl 
and fungi, wherein the bacteria are the main factors purifying wastewater (Pseudomonas, Acinetebacterium, Zooglea, Enterobacteriae, Micrococcus) [4-8].

Characteristics of activated sludge, the composition of their biocenosis, the size and shape of the flocs, and also the surface area value depend on the composition and type of raw wastewater to a large extent, as well as on the treatment technology (system of aeration, sedimentation conditions, way of pursuing recirculation of sludge, i.e. sludge pumping conditions), etc. [8-10]. Inflow of industrial wastewater to the treatment system can cause various kinds of disruptions of treatment plant operation, and also negatively affect the quality of activated sludge flocs. The dispersive growth of microorganisms is one of the phenomena that may occur and increase of amount of bacteria unable to bioflocculate be observed. It is characterized by a large number of free-floating bacteria. They flow out of the treatment plant with purified wastewater, because they do not sediment in secondary settling tank. Another negative effect of industrial wastewater flow is the phenomenon of sludge bulking. There are two types of the sludge bulking: filamentous and non-filamentous. The filamentous bulking is caused by excessive growth of filamentous forms of bacteria [11-13]. The non-filamentous bulking, characterized by a decrease of cohesion and the density of flocs, causes that the density of flocs is similar to that of water (difficulties with settling of that flocs are observed). Ye et al. [11] demonstrated a significant impact of the $\mathrm{C} / \mathrm{N}$ ratio on the floc size and volume index. They showed that a rapid decrease and rapid increase in the value of $\mathrm{C} / \mathrm{N}$ ratio caused a reduction of average floc size and an increase of the volume index. As a result, the deterioration of settling properties was observed. Thus, unfavorable value of $\mathrm{C} / \mathrm{N}$ ratio (which can occur in industrial wastewater) significantly affects the characteristics of the activated sludge. Furthermore, the impact of pollutants contained in industrial wastewater can cause rapid dispersion of flocs (the phenomenon of "pin-point floc"). At this time, an average size of floc is decreasing significantly, and the flocs, smaller than $20 \mu \mathrm{m}$, begin to predominate in activated sludge. Simultaneously, high turbidity of treated sewage and a very low value of sludge volume index are observed [14]. Moreover, industrial wastewater may contain different kind of specific substances, which can be toxic to microorganisms of activated sludge. As a result, their growth and their reproduction are inhibited $[15,16]$.

Landfill leachate is the industrial wastewater containing various kinds of compounds which can affect biological treatment. It is characterized by a high concentration of nitrogen and salinity. Moreover, an unfavorable value of $\mathrm{C} / \mathrm{N}$ ratio can be observed. Furthermore, leachate can also include adsorbable organic halides (AOX), which are classified as almost non-biodegradable substances.

In the work, the influence of chemically pretreated landfill leachate on characteristics of activated sludge in a biological treatment system has been investigated. Moreover, the changes of activated sludge floc size, floc shape coefficient and the volume index were determined. 


\section{METHODS}

The pretreatment process of the leachate has been chosen in the preliminary studies, conducted by the authors at the Department of Water and Wastewater Technology of Silesian University of Technology. During the studies, the leachate from "young" municipal landfill (at the age of 5 years was treated. The leachate was pretreated by using a two-step chemical process. At the first stage, a coagulation process was carried out. Then chemical oxidation using hydrogen peroxide was conducted. PIX 110-10 was used as a reagent during coagulation in the dose of $1.7 \mathrm{~g} / \mathrm{dm}^{3}$. The coagulation/flocculation process was conducted in a conventional jar-test apparatus (Flocculator SW1) equipped with 6 beakers $1 \mathrm{dm}^{3}$ in volume. The parameters of the process are given in Table 1.

Table 1

Parameters of the first stage of two-step chemical pretreatment process.

Coagulation by PIX 110-10

\begin{tabular}{|c|c|c|c|c|c|}
\hline \multirow{2}{*}{$\begin{array}{c}\text { Dose of } \\
\text { PIX 110-10 } \\
{\left[\mathrm{g} / \mathrm{dm}^{3}\right]}\end{array}$} & \multicolumn{2}{|r|}{ Fast mixing } & \multicolumn{2}{|c|}{ Flocculation } & \multirow{2}{*}{$\begin{array}{c}\mathrm{pH} \\
\text { of flocculation }\end{array}$} \\
\hline & $\begin{array}{l}\text { Time } \\
{[\min ]}\end{array}$ & $\begin{array}{c}\text { Speed of mixing } \\
{[\mathrm{rpm}]}\end{array}$ & $\begin{array}{l}\text { Time } \\
{[\mathrm{min}]}\end{array}$ & $\begin{array}{c}\text { Speed of mixing } \\
{[\mathrm{rpm}]}\end{array}$ & \\
\hline 1.7 & 1 & 200 & 20 & 35 & 5.0 \\
\hline
\end{tabular}

$\mathrm{H}_{2} \mathrm{SO}_{4}$ was used to adjust $\mathrm{pH}$ of the leachate, as $\mathrm{pH}$ of the raw leachate was approximately 7. After $30 \mathrm{~min}$ of settling, the supernatant liquid was oxidized, with $1 \mathrm{~g}$ of $\mathrm{H}_{2} \mathrm{O}_{2} / \mathrm{dm}^{3}$ at $\mathrm{pH} 3.0\left(\mathrm{H}_{2} \mathrm{SO}_{4}\right.$ was used as well). This process was conducted in beakers, each in volume of $1 \mathrm{dm}^{3}$, equipped with magnetic stirrers at the speed of $250 \mathrm{rpm}$.

Table 2

Parameters of the second stage of the chemical pretreatment process.

Chemical oxidation

\begin{tabular}{|c|c|c|c|}
\hline $\begin{array}{c}\text { Dose of } \mathrm{H}_{2} \mathrm{O}_{2} \\
{\left[\mathrm{~g} / \mathrm{dm}^{3}\right]}\end{array}$ & Initial $\mathrm{pH}$ & $\begin{array}{c}\text { Reaction time } \\
{[\mathrm{min}]}\end{array}$ & Final $\mathrm{pH}$ \\
\hline 1.0 & 3.0 & 60 & 8.5 \\
\hline
\end{tabular}

After the oxidation, $\mathrm{pH}$ of the leachate was increased up to 8.5 using $\mathrm{NaOH}$ (Table 2). It was mixed for 30 min to decompose residual hydrogen peroxide. Characteristics of the raw and pretreated leachate are shown in Table 3. During the first three weeks, a biological system was being fed by the raw municipal wastewater (without pretreated leachate). Municipal wastewater and activated sludge were collected from the same treatment plant. After adaptation of activated sludge to the laboratory conditions, the main experiments were carried out. 
Characteristics of municipal wastewater, raw and pretreated leachate

\begin{tabular}{|l|c|c|c|c|c|}
\hline \multicolumn{1}{|c|}{ Wastewater } & $\begin{array}{c}\mathrm{COD} \\
{\left[\mathrm{mg} \mathrm{O}_{2} / \mathrm{dm}^{3}\right]}\end{array}$ & $\begin{array}{c}\mathrm{BOD}_{5} \\
{\left[\mathrm{mg} \mathrm{O}_{2} / \mathrm{dm}^{3}\right]}\end{array}$ & $\begin{array}{c}\mathrm{N} \text { total } \\
{\left[\mathrm{mg} \mathrm{N}_{\left.\mathrm{dm}^{3}\right]}\right]}\end{array}$ & $\begin{array}{c}\mathrm{P}_{\text {total" }} \\
{\left[\mathrm{mg} \mathrm{P}_{\left.\mathrm{dm}^{3}\right]}\right]}\end{array}$ & $\begin{array}{c}\mathrm{N}^{-\mathrm{NH}_{4}} \\
{\left[\mathrm{mg} \mathrm{N} / \mathrm{dm}^{3}\right]}\end{array}$ \\
\hline Municipal & $273.0-567.7$ & $79.0-282.3$ & $42.6-61.2$ & $6.3-10.2$ & $20.4-39.1$ \\
\hline Raw leachate & $3087.6-3136$ & $350-500$ & $2150-2625$ & 36.4 & $1029-2300$ \\
\hline Pretreated leachate & $2156.2-2509.6$ & $100.2-132.3$ & $1778-1870$ & $5.0-5.6$ & $1600-1680$ \\
\hline
\end{tabular}

The pretreated leachate was mixed with municipal wastewater in the proportions resulting from the volumetric share of leachate. This mixture was used to feed the biological treatment system (Fig. 1). During the tests, the volumetric share of leachate in influent mixture was gradually increasing from 2.5 up to 15 vol. \%.

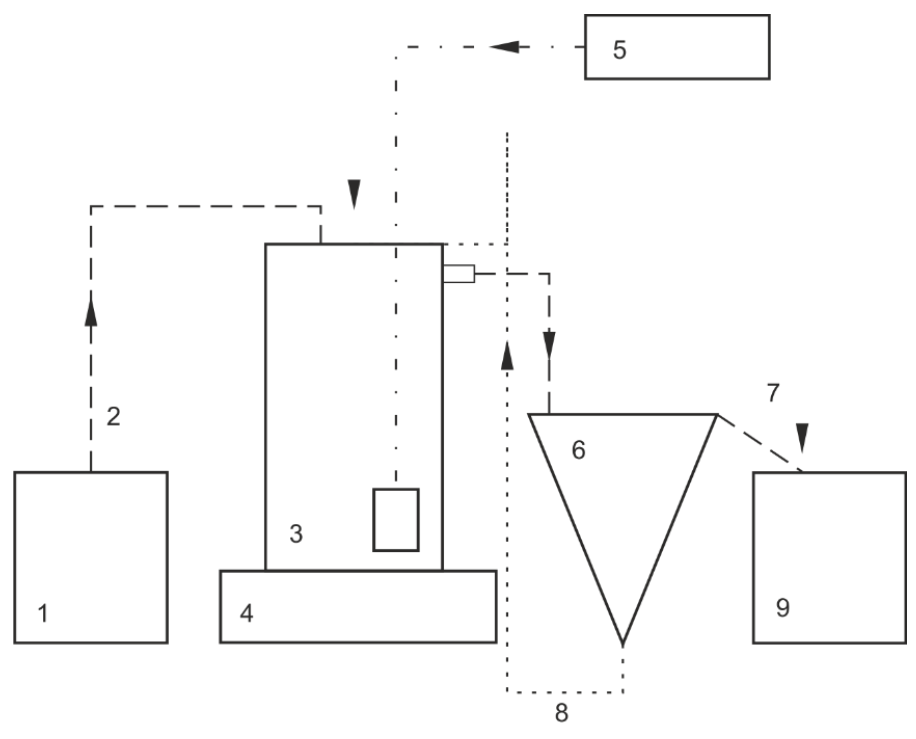

Fig. 1. Scheme of the biological treatment system of pre-treated leachate: 1 - tank of raw wastewater, 2 - inflow of raw wastewater, 3 - bioreactor, 4 - magnetic stirrer, 5 - aeration blower, 6 - secondary settling tank, 7 - outflow of treated wastewater, 8 - sludge recirculation, 9 - tank of treated sewage

A bioreactor was aerated with a blower and its contents was mixed with a magnetic stirrer, in order to maintain an uniform concentration of dissolved oxygen in the whole its volume (in the range of $1.5-2.5 \mathrm{mg} \mathrm{O} / \mathrm{dm}^{3}$ ). To obtain a suitable concentration of activated sludge in the aeration tank $\left(3.0-4.0 \mathrm{~g}\right.$ TS/ $\left.\mathrm{dm}^{3}\right)$, an external recirculation of sludge from the secondary settling tank was carried out (by a peristaltic pump). The wastewater was fed to the reactor by a peristaltic pump. The flow rate of wastewater 
equaled $3.0 \mathrm{dm}^{3} / \mathrm{d}$. The hydraulic retention time of the mixture of wastewater and leachate equaled $1.5 \mathrm{~d}$, and the external recirculation rate was $100 \%$ flow.

During the studies, a control of characteristics of activated sludge was carried out, consisting of:

- estimation of dissolved oxygen in the bioreactor using oxygen meter Oxi 538 by WTW,

- estimation of the volume index based on settling properties after $30 \mathrm{~min}$ and on the concentration of activated sludge [17],

- measurement of the floc size and the coefficient of floc shape by the microscopic method [18].

During the measurement of the floc size, the probe of activated sludge was collected by pipette with a hole at the end to prevent the deformation of the flocs. In each case 50 flocs were measured. During the control of the sludge, four probes were made and the observations were carried out in 28 fields of view. The average size of the activated sludge flocs $A S_{f}$ is the arithmetic mean of the 50 measured floc sizes $S_{f}$

$$
A S_{f}=\frac{\sum S_{f}}{50}
$$

The size of an individual floc was determined as the arithmetic mean ratio of its length $L_{f}$ to width $W_{f}$. The length was defined as the largest dimension of the floc and the width - the smallest dimension perpendicular to the length.

$$
S_{F}=\frac{L_{f}+W_{f}}{2}
$$

The coefficient of floc shape $S h C$ was defined as the ratio of the length to width

$$
S h C=\frac{L_{f}}{W_{f}}
$$

The average coefficient of the floc shape $A S h C$ was calculated as the arithmetic mean of the 50 measured sludge flocs

$$
A S h C=\frac{\sum S h C}{50}
$$

where: $A S_{f}$ is the average floc size, $\mu \mathrm{m}, S_{f}-$ the size of individual floc, $\mu \mathrm{m}, S h C-$ the coefficient of floc shape of an individual floc, $L_{f}-$ the length of an individual floc, $\mu \mathrm{m}$, $W_{f}$ - the width of an individual floc, $\mu \mathrm{m}, A S h C$ - the average coefficient of floc shape. 


\section{RESULTS AND DISCUSSION}

Raw leachate had a high COD, related to the content of organic matter and nitrogen compounds, mainly ammonia nitrogen. However, the content of organic matter $\left(\mathrm{BOD}_{5}\right)$ was relatively low. According to the landfill age, the value of $\mathrm{BOD}_{5} / \mathrm{COD}$ ratio in leachate should be approximately 0.5 . In the case of the leachate under examination, the $\mathrm{BOD}_{5} / \mathrm{COD}$ ratio was in the range of $0.11-0.15$. This indicates that the leachate contained primarily organic compounds which were hardly or non-biodegradable. After the pretreatment process, the values of $\mathrm{COD}$ and $\mathrm{BOD}_{5}$ decreased by $20-30$ and $71-74 \%$, respectively. However, the content of nitrogen compounds decreased slightly (only by $18 \%$ ), while the concentration of phosphorus significantly changed (by 85-86\%). The pretreated leachate was characterized by a relatively high COD, related to large amount of organic matter and nitrogen, particularly ammonium nitrogen. In the case of raw municipal wastewater used in the study, the concentration of organic compounds was typical of that kind of wastewater. However, it was characterized by a relatively high content of biogenic compounds (Table 3).

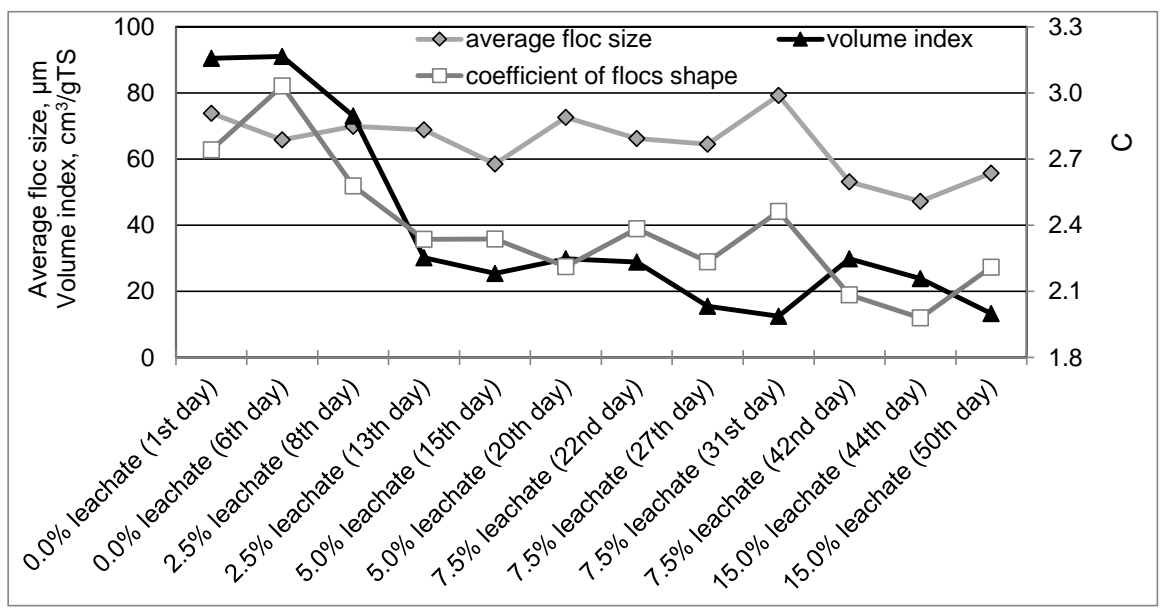

Fig. 2. Changes of average floc size, volume index and coefficient of floc shape during the study

The addition of pretreated leachate to wastewater resulted in a significant reduction of the volume index (Fig. 2). When only raw municipal wastewater (without addition of leachate) flew into bioreactor, the volume index value was approximately $90 \mathrm{~cm}^{3} / \mathrm{g}_{\text {TS }}$. Thus, the sludge was characterized by normal settling properties. The addition of the first dose of pretreated leachate ( $2.5 \mathrm{vol}$. \% of leachate in the wastewater inflow) resulted in a decrease of the volume index (it increased to a value of 70 and then even up to $\left.30 \mathrm{~cm}^{3} / \mathrm{g}_{\mathrm{TS}}\right)$. In the following days of the experiments, the values of this parameter still had a decreasing trend, as the share of leachate was increased. However, this decrease was not as significant as during the first days, and the volume index varied in the 
range of $12-30 \mathrm{~cm}^{3} / \mathrm{g}_{\text {TS }}$. Low values of the volume index may indicate a considerable dispersion of activated sludge flocs. Thus, a part of flocs settled very rapidly, while another ones were floating in the supernatant liquid $[18,19]$. That phenomenon was observable as a visible turbidity of supernatant liquid. However, the measurements of average floc size did not indicate a significant breakdown of flocs. The average size of flocs was very similar, in the range of $60-80 \mu \mathrm{m}$. The decrease of the floc size was observed only in last few days of the study, when the share of leachate was 15 vol. \% in the mixture flowing into the bioreactor (average floc size was approximately $50 \mu \mathrm{m}$ ) (Fig. 2).

A decreasing trend of the average coefficient of shape of the activated sludge flocs $A S h C$ was observed all over the study. During the adaptation period, the $A S h C$ reached 3 . This proved, that elongated flocs were the most common forms occurring in the sludge. In the first day of feeding the bioreactor by the mixture of municipal wastewater and leachate (volume share of the leachate equaled 2.5 vol. \%) it reached the value of 2.6. During the following days (when the leachate share remained 2.5 vol. \%) the $A S h C$ decreased to 2.3 and then it remained almost constant (in the range of 2.2-2.5). A significant reduction of the $A S h C$ (up to 2.0) was observed only at the final stage of the experiment (on 42nd day of study). Therefore, it can be concluded, that slightly elongated shapes of flocs dominated in activated sludge for vast majority of experiment. It is proved by the values of that coefficient, which were close to 2.3. Within certain ranges of share of leachate, it was also observed, that values of $A S h C$ and volume index showed common trends (Fig. 2). This could indicate, that the increase of the amount of elongated flocs can cause a deterioration of the settling properties of the sludge. In contrast, a decreasing value of the $A S h C$ indicated an occurrence of flocs more similar to the oval, which were characterized by better settling properties. As the result, a decrease of volume index was also observed. Furthermore, a common trend of the average floc size and average coefficient of floc shape was observed, when the share of leachate in feeding mixture was $15 \mathrm{vol} . \%$. It can be concluded that small flocs had their shape more similar to oval, while the large flocs were more elongated.

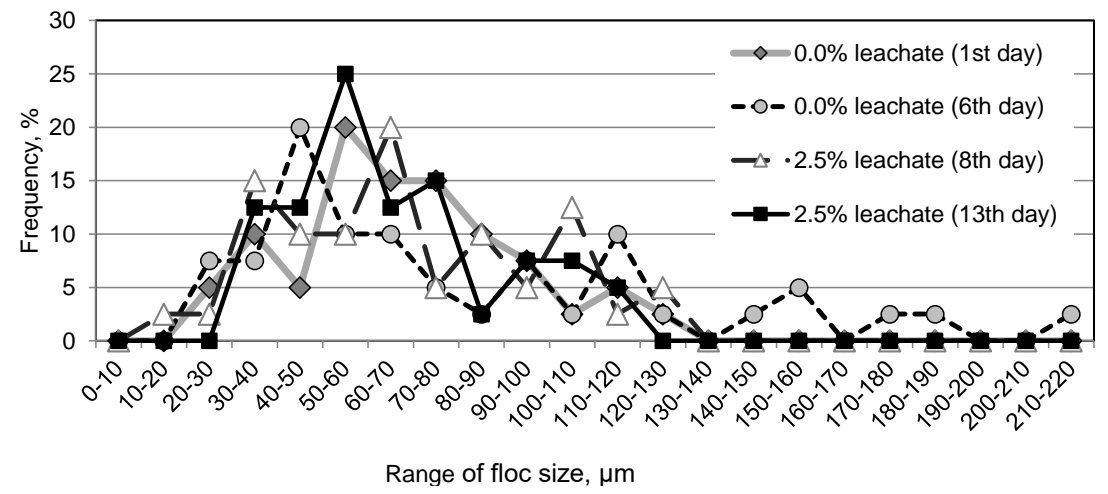

Fig. 3. Frequency distribution of flocs of various sizes during the study (from 1st to 13th day of the research) 


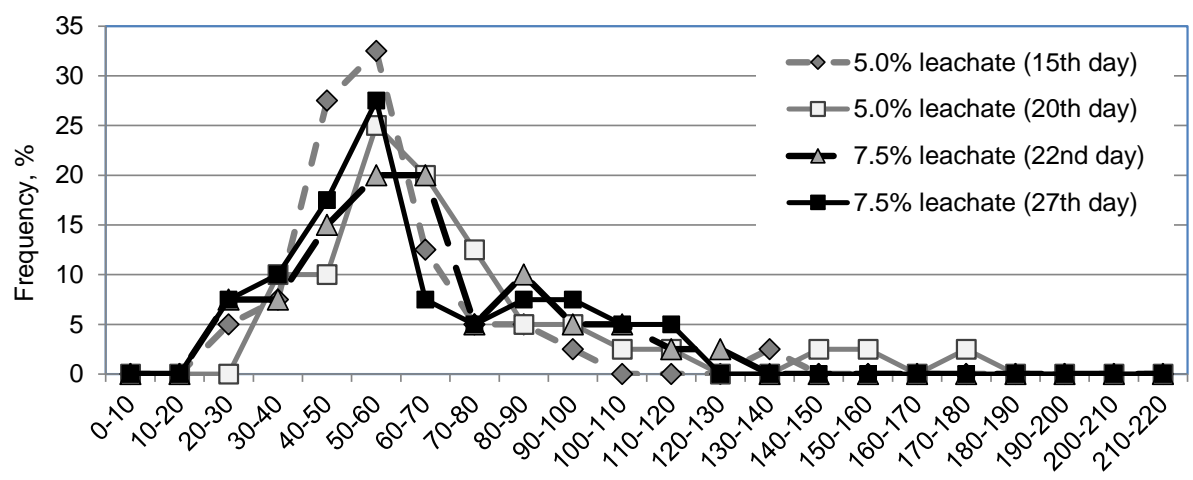

Range of floc size, $\mu \mathrm{m}$

Fig. 4. Frequency distribution of flocs of various sizes during the study (from 15 th to 27 th day of research)

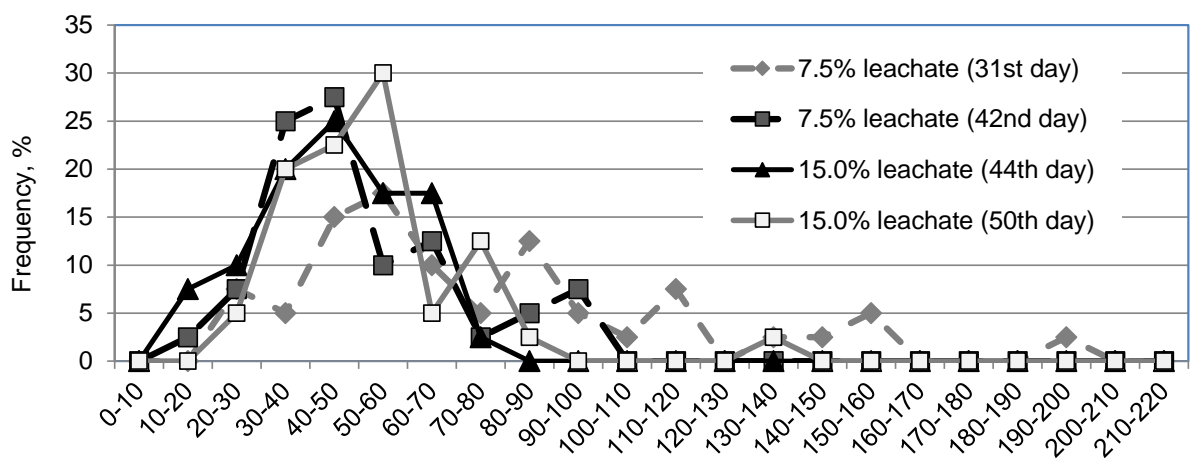

Range of floc size, $\mu \mathrm{m}$

Fig. 5. Frequency distribution of flocs of various sizes during the study (from 31 st to 50th day of the research)

Based on the measurement of the average floc size $A S_{f}$, an analysis of its distribution was carried out (Figs. 3-5). That analysis showed significant changes of floc size of activated sludge. The frequency of larger flocs gradually decreased as the dose of the pretreated leachate in the mixture feeding bioreactor was increased. Moreover, at the same time, an increasing number of small ones was noted. When the leachate share in mixture feeding bioreactor was in the range from 2.5 to 7.5 vol. \%, flocs larger than $100 \mu \mathrm{m}$ disappeared. When the volume share of leachate was $15.0 \mathrm{vol} . \%$, flocs smaller than $90 \mu \mathrm{m}$ mainly occurred. The amount of agglomerates smaller than $60 \mu \mathrm{m}$ gradually increased during the study. Initially, when the share of the leachate did not exceed 5 vol. \% in the feeding mixture, the total frequency of flocs smaller than $50 \mu \mathrm{m}$ was approximately $40 \%$. When the amount of leachate increased up to 7.5 vol. \% and higher, the 
number of the flocs smaller than $50 \mu \mathrm{m}$ increased up to more than $70 \%$ of the total amount of measured flocs. In addition, at the final stage of the study (day 31st), very small size flocs (smaller than $20 \mu \mathrm{m}$ ) were observed in the sludge. The negative impact of pretreated landfill leachate on the flocs' structure was proven by the gradual fragmentation of sludge flocs. This dispersion confirmed that the phenomenon of "pin-point floc", previously established based on the measurements of the volume index, occurred. Decreasing value of $\mathrm{C} / \mathrm{N}$ ratio in wastewater flowing into the bioreactor could be the reason of fragmentation of sludge. The content of nitrogen compounds in leachate was much higher than its concentration in municipal wastewater. Therefore, upon increasing volume share of the leachate in feeding wastewater, the decrease of $\mathrm{C} / \mathrm{N}$ ratio was observed. At the beginning of experiments, the $\mathrm{C} / \mathrm{N}$ ratio was approximately 5 , and at the end it decreased even up to 0.14 (when the volume share of the leachate was $15 \mathrm{vol}$. \%).

Despite small flocs consisting the activated sludge, it is able to purify wastewater effectively. However, the technological exploitation of the treatment plant where this phenomenon occurs, can cause problems. An outflow of activated sludge from the treatment system may be observed. It is connected with low settling properties of very small flocs, which density is similar to the density of water. It may cause difficulties in maintaining a constant mass of activated sludge in bioreactors because uncontrolled outflow of flocs with the purified wastewater occurs. In addition, the activated sludge flocs contain contaminants that have been removed from the wastewater during the biochemical treatment processes causing the exceeding of acceptable values of pollutants in treated wastewater.

\section{CONCLUSIONS}

The study showed a significant impact of chemically pretreated landfill leachate (by a coagulation and oxidation with hydrogen peroxide) on the structure of activated sludge. Based on the study, the following conclusions can be concluded:

- Increasing the volume share of the leachate caused a gradual reduction of the amount of large flocs (larger than $60 \mu \mathrm{m}$ ) and increase in the number of small and very small ones (smaller than $30 \mu \mathrm{m}$ ).

- The inflow of the pretreated leachate into biological treatment system caused a rapid decrease in the value of the volume index: it equaled $30 \mathrm{~cm}^{3} / \mathrm{g}_{\mathrm{ts}}$ when the volume share of the leachate was $2.5 \mathrm{vol} . \%$.

- When the rapid sludge settling process occurred, a significant turbidity of supernatant liquid was observed (caused by flocs of a very small size).

- The maximum allowable volume share of the chemically pretreated leachate in the feeding mixture should not exceed 5 vol. $\%$ to avoid the dispersion of flocs. 
- The method used to pretreat the landfill leachate did not allow one to obtain an expected effect. The maximum permissible volume share of the raw leachate was also 5 vol. \%.

\section{REFERENCES}

[1] ECKenfelder W.W., Jr., Musterman J.L., Activated Sludge Treatment of Industrial Wastewater, Technomic Publishing, Co., Lancaster 1995.

[2] Orhon D., BABuna F.G., KARAHAN O., Industrial Wastewater Treatment by Activated Sludge, IWA Publishing, London 2011.

[3] DuAn Z., Microbial degradation of phenol by activated sludge in a batch reactor, Env. Prot. Eng., 2011, 37 (2), 53.

[4] Microbial Ecology of Activated Sludge, R. Seviour, P.H. Nielsen (Eds.), IWA Publishing, London 2010.

[5] Guide of exploiter of wastewater treatment plant, Z. Dymaczewski, J.A. Oleszkiewicz, M.M. Sozański (Eds.), Polskie Zrzeszenie Inżynierów i Techników Sanitarnych, Poznań 1997 (in Polish).

[6] Pholchan M.K., Baptista J.D.C., DavenPort R.J., Curtis T.P., Systematic study of the effect of operating variables on reactor performance and microbial diversity in laboratory-scale activated sludge reactors, Water Res., 2010, 44, 1341.

[7] Biological Wastewater Treatment: Principles, Modelling and Design, M. Henze, M. van Loosdrecht, G. Ekama, D. Brdjanovic (Eds.), IWA Publishing, London 2011.

[8] Spellman F.R., Handbook of water and wastewater treatment plant operations, CRC Press/Taylor and Francis, Boca Raton 2009.

[9] Jin B., WiLÉN B.-M., LANT P., A comprehensive insight into floc characteristics and their impact on compressibility and settleability of activated sludge, Chem. Eng. J., 2003, 95, 221.

[10] Ye F., PENG G., Li Y., Influences of influent carbon source on extracellular polymeric substances (EPS) and physicochemical properties of activated sludge, Chemosph., 2011, 84, 1250.

[11] YE F., YE Y., Li Y., Effect of C/N ratio on extracellular polymeric substances (EPS) and physicochemical properties of activated sludge flocs, J. Hazard. Mater., 2011, 188, 37.

[12] Martins A.M.P., Pagilla K., Heijnen J.J., VAn Loosdrecht M.C.M., Filamentous bulking sludge. A critical review, Water Res., 2004, 38, 793.

[13] Hwang Y., Tanaka T., Control of Microthrix Parvicella foaming in activated sludge, Water Res., 1998, 32 (5), 1678.

[14] KoŚCIELNIAK H., BARBUSIŃSKi K., Disturbances of the sludge process during treatment of wastewater from the chemical industry, Polish Conference of Science and Technology: Achievements and problems of treatment of industrial wastewater, 17-18 September 1998, Chorzów (in Polish).

[15] Vaiopoulou E., GiKas P., Effects of chromium on activated sludge and on the performance of wastewater treatment plants. A review, Water Res., 2012, 46, 549.

[16] CHEN G.-W., YU H.-Q., XI P.-G., Influence of 2,4-dinitrophenol on the characteristics of activated sludge in batch reactors, Biores. Technol., 2006, 98, 729.

[17] Standard Methods for the Examination of Water and Wastewater, L.S. Clesceri, A.E. Greenberg, A.A. Eaton (Eds.), American Public Health Assoc., Washington 1998.

[18] BARBUSIŃSKI K., KoŚCIELNIAK H., Influence of substrate loading intensity on floc size in activated sludge, Water Res., 1995, 29, 1703.

[19] NIELSEN P.H., KEIDING K., Disintegration of activated sludge flocs in presence of sulfide, Water Res., 1998, 32, 313. 